\title{
Changing Trends in Mastectomy and Breast Reconstruction. Analysis of a Single-institution Experience Between 2004-2016
}

\author{
TOMMASO SUSINI ${ }^{1}$, IRENE RENDA ${ }^{1}$, MILO GIANI $^{1}$, ARIANNA VALLARIO ${ }^{1}$, JACOPO NORI $^{2}$, \\ ERMANNO VANZI ${ }^{2}$, ALESSANDRO INNOCENTI $^{3}$, GIULIA LO RUSSO ${ }^{3}$ and SIMONETTA BIANCHI ${ }^{4}$ \\ ${ }^{1}$ Breast Unit, Gynecology Section, Department of Health Sciences, University of Florence, Florence, Italy; \\ ${ }^{2}$ Diagnostic Senology Unit, Azienda Ospedaliero-Universitaria Careggi, Florence, Italy; \\ ${ }^{3}$ Plastic and Reconstructive Sugery Unit, Azienda Ospedaliero-Universitaria Careggi, Florence, Italy; \\ ${ }^{4}$ Pathology Unit, Department of Health Sciences, University of Florence, Florence, Italy
}

\begin{abstract}
Background/Aim: Recently, "conservative" mastectomy with immediate breast reconstruction $(M-R)$ has become the gold standard when the breast must be removed. We analyzed the evolution in the choice of mastectomy type in our Unit, focusing on factors associated with renounce to reconstruction and risk factors for its failure. Patients and Methods: Clinical-pathological and surgical features of 132 patients who underwent mastectomy in our Unit from 2004 to 2016 were analyzed. $M-R$ rate and different mastectomy techniques' rates between 2004-2009 and 2010-2016 were compared. Results: $M-R$ was associated with younger age at diagnosis $(p<0.001)$ and early tumor stage $(p=0.03) . M-R$ rate increased from $49.1 \%$ to $72.2 \%(p=0.002)$ in the last years, with prominent use of nipple-sparing-mastectomy $(p<0.001) . M-R$ failure rate was associated with previous or subsequent irradiation/chemotherapy in $92.3 \%$ of cases. Conclusion: M-R and particularly nipple-sparing-mastectomy represented the standard in more recent years; reconstruction failure was associated with irradiation/chemotherapy, especially in implant-based reconstructions.
\end{abstract}

Breast cancer is the leading cause of death in women worldwide representing about $23 \%$ of all cancers (1). Over the last century, improvements in diagnosis and treatment of breast cancer, determined a remarkable advancement achieving the development of less invasive and mutilating surgical approaches (2). In particular, thanks to Veronesi's

Correspondence to: Tommaso Susini, MD, Ph.D., Head, Breast Unit, Gynecology Section, Department of Health Sciences, University of Florence, Largo Brambilla 3, 50134, Florence, Italy. Tel: +390552751752, e-mail: tommaso.susini@unifi.it

Key Words: Mastectomy, immediate reconstruction, reconstructive techniques, nipple-sparing mastectomy, breast implants, reconstruction failure, reconstruction with autologous tissues.
(3) and Fisher's (4) studies, the breast conserving surgery (BCS) (quadrantectomy, wide resection or lumpectomy with axillary dissection) associated with post-operative radiation therapy, was developed. At present, BCS is the standard of treatment for most women with early-stage breast carcinoma (5). However, a number of patients still must or wish to undergo mastectomy (6). Madden modified radical mastectomy (MRM) represented the gold-standard technique for a long time, until the introduction of plastic surgery concepts to breast cancer treatment have given birth to a new approach, commonly indicated as "oncoplastic surgery" (7).

In the last decades, the oncoplastic principles, besides offering better cosmetic results in conservative breast procedures, also opened the door for the development of the so-called "conservative mastectomies" (8). These operations preserve the cutaneous and subcutaneous breast envelope in order to facilitate immediate breast reconstruction and offer good cosmetic results, similar, if not better, to those obtained with BCS. The introduction of "conservative mastectomies" and, particularly, of nipple-sparing mastectomy (NSM) has recently boosted the choice of mastectomy rather than BCS, with a consequent increase in the rate of these operations in the last years (9-11). "Conservative mastectomies" include skin sparing mastectomy (SSM) (12), NSM, which was described in 1951 by Rice and Stickler for benign lesions (13) and was recently validated for breast cancer treatment with preservation of the nipple-areola complex (NAC), and nipplesparing skin-reducing mastectomy (SRM), described in 2006 for treatment of large breasts with ptosis (14).

At present, immediate breast reconstruction is offered to the majority of patients who deserve mastectomy and its feasibility represents a marker of quality assessment in breast cancer surgery. Whether use prosthetic material or autologous tissue for breast reconstruction is often a matter of debate.

In the present study, all the mastectomy procedures performed in our Unit from 2004 to 2016 were reviewed aiming at the observation of the changing trends in 
mastectomy over the time; the identification of the factors associated with renounce to immediate breast reconstruction; the analysis of the complication rate associated with different techniques of breast reconstruction, according to clinical and physical characteristics of patients, to identify the optimal reconstruction technique in the individual patient.

\section{Patients and Methods}

Surgical procedure. All the breast cancer operations performed by the same surgeon (T.S.) at the Breast Unit of the Gynecology section, Department of Health Science, Careggi Hospital, University of Florence, from January 2004 to June 2016 were retrospectively reviewed. Breast reconstructions were done in collaboration with the Plastic and Reconstructive Surgery Unit, Careggi Hospital, University of Florence.

Patient selection. The study focused on 132 patients submitted to mastectomy, with or without reconstruction. We compared MRM without reconstruction (MRM-NR) to all other techniques providing immediate breast reconstruction (M-R), including MRM with reconstruction (MRM-R), SSM, NSM and SRM. We arbitrarily split our study period into two time intervals (2004-2009 vs. 2010-2016) to compare the rate of immediate reconstruction as well as the incidence of the different type of mastectomy between the two periods. Patients' records were analyzed to assess demographic, clinical, pathological and surgical data.

Compliance with ethical standards. All procedures performed in studies involving human participants were in accordance with the ethical standards of the institutional and/or national research committee and with the 1964 Helsinki declaration and its later amendments or comparable ethical standards.

Statistical analysis. Patient characteristics were analyzed using Fisher's exact test or Chi-squared test, as appropriate (IBM SPSS Statistics for Windows, Version 22.0. Armonk, NY: IBM Corp.). A $p$-value $<0.05$ was considered statistically significant.

\section{Results}

Factors associated with immediate breast reconstruction. During the study period, 675 women were operated on for breast cancer; in 543 cases $(80.4 \%)$, a breast conserving operation was performed, whereas 132 patients $(19.6 \%)$ required mastectomy. Overall, in the mastectomy group, 49 patients $(37.1 \%)$ did not receive reconstruction (MRM-NR) whereas in 83 women $(62.9 \%)$ an immediate breast reconstruction (M-R) was associated. In particular, among M-R patients, we recorded 13 (15.7\%) MRM-R, $22(26.5 \%)$ SSM, 38 (45.8\%) NSM, and 10 (12\%) SRM.

Focusing on factors associated with immediate reconstruction, we investigated patients' age at diagnosis. The mean age at diagnosis for the MRM-NR group was 70 years, compared to 51 years for the M-R patients $(p<0.001)$. Furthermore, considering three age groups, namely $\leq 50$ years $(n=51), 51-69$ years $(n=50)$, and $\geq 70$ years old $(n=31)$, we evaluated the prevalence of immediate reconstruction. In $27 / 31(87.1 \%)$ of the oldest women, mastectomy was performed without breast reconstruction. Conversely, among the youngest patients $\mathrm{M}-\mathrm{R}$ was predominant, representing $45 / 51(88.2 \%)$ of cases. Also among patients with intermediate age M-R was highly prevalent, as it was performed in 34/50 (68\%) women $(p<0.001)$.

We also evaluated the role of tumor stage for choosing between MRM-NR and M-R. In our series, $44.9 \%$ (22/49) of women treated without breast reconstruction presented a T3 stage cancer (TNM), whereas among patients resorted to M$\mathrm{R}$ the rate of $\mathrm{T} 3$ stage was $26.5 \%(22 / 83)(p=0.03)$. In addition, focusing on the 22 women $\leq 70$ years old who declined breast reconstruction, it resulted that $11 / 22$ patients $(50 \%)$ presented with locally advanced disease (T4 and/or N3 stage) and $3 / 22(13.6 \%)$ additional patients showed previous exposure to radiotherapy.

Comparison between 2004-2009 and 2010-2016. When considering the proportion of breast conserving procedures and mastectomy over the years, we found that mastectomy rate raised from $16.7 \%$ in the years $2004-2009$, to $22.1 \%$ in the years 2010-2016 ( $p=0.01)$. Then, analyzing the M-R rate, we pointed out a significant difference between the two time periods, with immediate breast reconstruction increasing from $49.1 \%$ in the former period to $72.2 \%$ in the latter period $(p=0.002)$ (Figure 1). We investigated the distribution of different types of M-R over the time. In the years 2004-2009, reconstruction procedures were SSM and MRM-R, representing $17 / 26$ cases $(65.4 \%)$ and $9 / 26$ cases $(34.6 \%)$, respectively. Since 2010, following the introduction of NSM the picture dramatically changed. In fact, in the years 2010-2016, NSM and SRM together represented $84.2 \%$ (48/57) of the M-R cases. Conversely, the use of SSM and MRM-R decreased to $8.8 \%$ $(5 / 57)$ and $7 \%(4 / 57)$, respectively $(p<0.001)$ (Figure 2).

Reconstruction techniques. Regarding the breast reconstruction techniques after mastectomy, 82 cases were treated with immediate (one-stage) or two-stage reconstruction, while only one case received standard delayed procedure. This last case represented a woman treated with neoadjuvant chemotherapy, MRM, and subsequent chest wall adjuvant irradiation because of the presence of multiple axillary lymph node metastases. In this patient, we ultimately resorted to delayed reconstruction with the deep inferior epigastric perforator (DIEP) flap.

Considering the type of M-R, we had implant-based procedures (tissue expander and prosthesis inserted under major pectoralis muscle), autologous methods [e.g. latissimus dorsi flap (LD), transverse rectus abdominis musculocutaneous flap (TRAM), and DIEP flap] and combined techniques (implant + autologous), as summarized in Table I. One patient, although scheduled for NSM with immediate reconstruction, did not undergo the reconstructive 


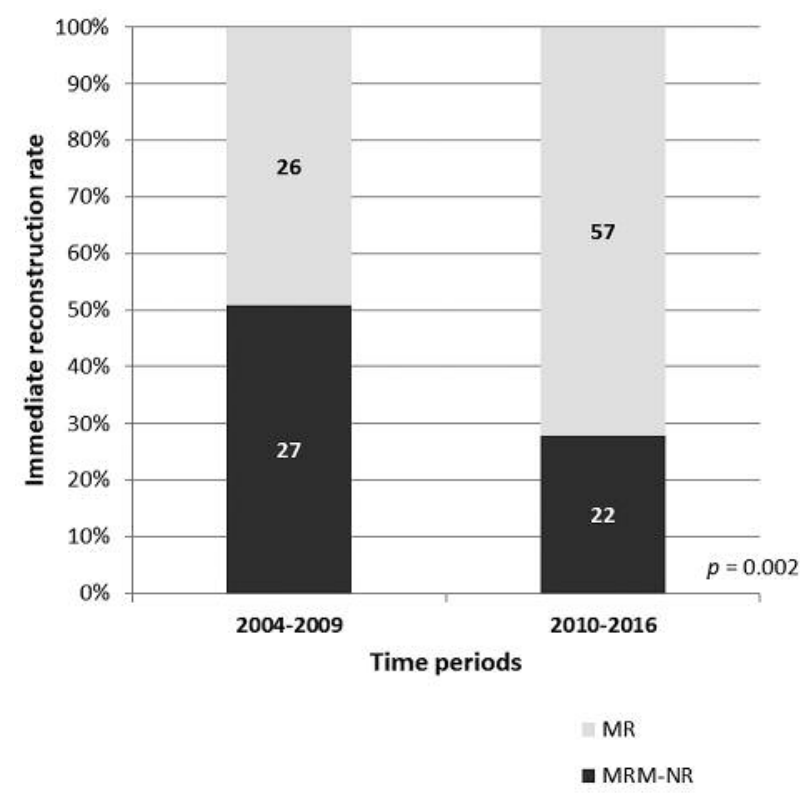

Figure 1. Distribution of mastectomy with and without immediate reconstruction in the years 2004-2009 and 2010-2016. MR, Mastectomy with immediate reconstruction; MRM-NR, mastectomy without reconstruction.

phase because of technical impossibility (atrophic major pectoralis muscle).

Particularly, among the 7 women treated with autologous reconstruction after MRM, the DIEP flap was performed in $3 / 7$, the TRAM flap in $3 / 7$ and the LD flap in $1 / 7$ cases. On the other hand, for the two patients who underwent to combined reconstruction after MRM, the procedure consisted in an expander implantation, subsequently replaced with a definitive prosthesis, associated with LD flap.

Considering the 47 patients submitted to NSM and SRM, 41 cases underwent implant-based reconstruction, 3 patients received autologous graft reconstruction with DIEP and in the remaining 3 cases a combined approach was used, with initial expander positioning and subsequent substitution with autologous tissue, using DIEP in 2 cases and LD flap in one case (Table I).

Factors associated with reconstruction failure. Finally, we analyzed complications after reconstruction and their relationship with different risk factors, particularly with chemotherapy and radiation therapy. We reported an overall reconstruction failure rate of $15.8 \%$ due to 13 major complications, namely: 4 cases of infection, 1 expander dislocation, 7 implant rejections and 1 case of hematoma and subsequent nipple areola complex (NAC) necrosis, all of them requiring implant removal. Distribution of major complications/failure for each type of M-R is summarized in Table II.

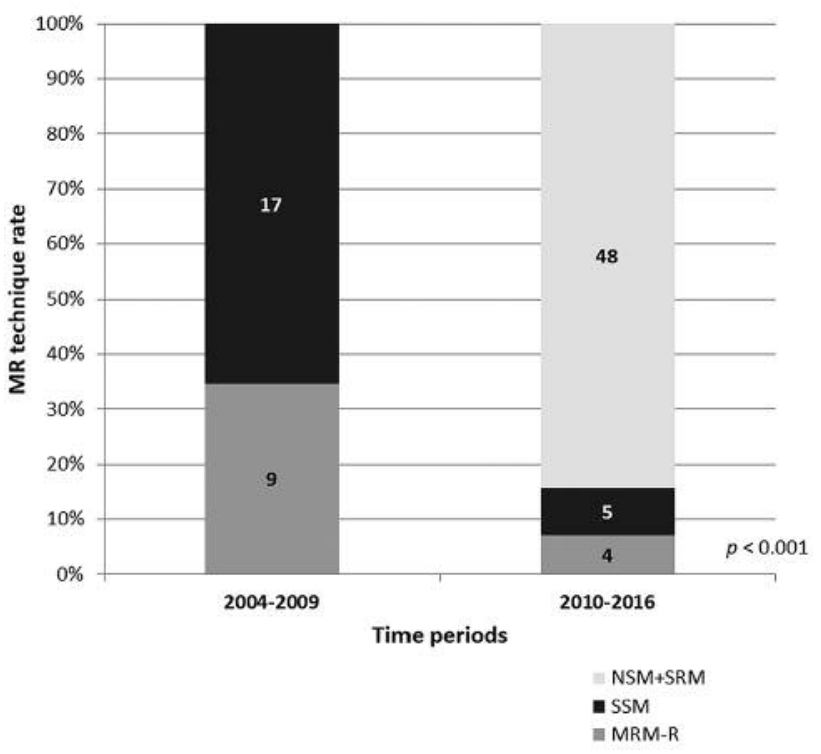

Figure 2. Mastectomy with immediate breast reconstruction according to different techniques in the years 2004-2009 and 2010-2016. Fisher's exact test comparing the different distribution of each mastectomy technique in the two periods showed a p-value $<0.001$ for each comparison. NSM, Nipple-sparing mastectomy; SRM, nipple-sparing skin-reducing mastectomy; SSM, skin-sparing mastectomy; MRM-R, madden modified radical mastectomy with reconstruction.

The majority of complications $12 / 13$ (92.3\%) occurred among cases that presented risk factors for reconstruction failure. In particular, 8/13 (61.5\%) patients were formerly treated with breast conserving therapy, followed by surgical field irradiation; among them, 3 were also exposed to adjuvant chemotherapy and one to adjuvant radiotherapy following the M-R procedure. Furthermore, 3/13 (23.1\%) showed exposition to both adjuvant irradiation and to chemotherapy, while $3 / 13$ (23.1\%) cases were exposed only to adjuvant chemotherapy.

\section{Discussion}

In the last decades, surgical treatment for breast cancer underwent significant improvements, becoming less mutilating and invasive. According to international trends (5), in our Unit we found that mastectomy rate and BCS rate were nearly $20 \%$ and $80 \%$, respectively. When mastectomy was required, immediate breast reconstruction was always considered and discussed with patients, in agreement with the latest recommendation for management of breast cancer patients (15). We found that renounce to immediate breast reconstruction was significantly associated with advanced age and/or advanced stage of disease and poor survival 
Table I. Immediate and delayed-immediate reconstruction methods after mastectomy.

\begin{tabular}{|c|c|c|c|c|c|c|}
\hline \multirow[b]{3}{*}{ Mastectomy type } & \multicolumn{6}{|c|}{ Reconstruction method } \\
\hline & \multicolumn{2}{|c|}{ Implant-based } & \multicolumn{2}{|c|}{ Autologous tissue } & \multicolumn{2}{|c|}{ Combination } \\
\hline & $\mathrm{n}$ & $\%$ & $\mathrm{n}$ & $\%$ & $\mathrm{n}$ & $\%$ \\
\hline MRM-R & $3 / 12$ & 25.0 & $7 / 12$ & 58.3 & $2 / 12$ & 16.7 \\
\hline SSM & $22 / 22$ & 100.0 & $0 / 22$ & - & $0 / 22$ & - \\
\hline NSM/SRM & $41 / 47$ & 87.2 & $3 / 47$ & 6.4 & $3 / 47$ & 6.4 \\
\hline Total & $66 / 81$ & 81.5 & $10 / 81$ & 12.3 & $5 / 81$ & 6.2 \\
\hline
\end{tabular}

MRM-R, Madden modified radical mastectomy with reconstruction; SSM, skin-sparing mastectomy; NSM/SRM, nipple-sparing mastectomy/nipplesparing-skin-reducing mastectomy.

expectation. This is in agreement with previous studies showing that mastectomy without reconstruction is usually limited to elderly women and/or patients with advanced disease (16), although these conditions do not represent an absolute contraindication to breast reconstruction. Recent studies showed the role of tumor molecular subtype on immediate breast reconstruction: HER2-overexpressing and triple-negative patients less likely underwent to $\mathrm{M}-\mathrm{R}$ compared to hormone-receptor-positive ones (17). The renounce to immediate reconstruction when such negative prognostic factors are present, may be explained by the higher rate of local recurrence shown by advanced stage/higher risk breast cancers (18). Thus, in such conditions, both physicians and women consider the aesthetic issue less relevant.

Despite the prevalence of BCS observed worldwide over the last two decades, we noticed in our series a trend reversal, with a significant increase of the mastectomy rate in the last years. Many factors could have contributed to the rise of mastectomy, a trend that was recorded also in other countries $(19,20)$. First, the increasing diagnosis of genetic mutations related to breast cancer development (e.g. BRCA1, BRCA-2) increased the use of prophylactic mastectomy (especially NSM) (21). In addition, the diffusion of preoperative magnetic resonance imaging (MRI), which is highly sensitive and poorly specific, may have influenced surgical approach, driving a shift towards mastectomy (19, 22). Then, the availability of "conservative mastectomies" techniques (especially NSM) has allowed immediate reconstruction with optimal aesthetic results and have boosted mastectomy indication, particularly to borderline candidates for BCS (23). In our series, we found that, since 2010, NSM has become the gold-standard mastectomy technique, supported by the evidence of its oncologic safety $(21,24,25)$. The use of other M-R techniques such as SSM is currently limited to a minority of cases with involvement of the NAC (26).
Table II. Failure rate according to type of $M-R$.

\begin{tabular}{lcc}
\hline M-R type & \multicolumn{2}{c}{ Failure rate } \\
\cline { 2 - 3 } & $\mathrm{n}$ & $\%$ \\
\hline MRM-R & $2 / 13$ & 15.4 \\
SSM & $4 / 22$ & 18.2 \\
NSM & $5 / 37$ & 13.5 \\
SRM & $2 / 10$ & 20.0 \\
\hline Total & $13 / 82$ & 15.8 \\
\hline
\end{tabular}

MRM-R, Madden modified radical mastectomy with reconstruction; SSM, skin-sparing mastectomy; NSM, nipple-sparing mastectomy; SRM, nipple-sparing-skin-reducing mastectomy.

Analyzing the factors associated with complications and reconstruction failure, we found a strong association with prior exposure to radiation therapy and with neoadjuvant and adjuvant chemotherapy, especially in implant-based reconstructions. The role of irradiation and chemotherapy on reconstruction failure was established in several studies (2729). Even with modern radiation delivery techniques, the complication rate for immediate breast reconstruction after post-mastectomy radiation therapy was very high, thus suggesting the use of delayed autologous tissue as the optimal approach in these patients or a delayed-immediate reconstruction at most. Our findings reinforce the existing evidence and suggest that autologous reconstructive methods are preferable than implant-based techniques in women presenting risk factors for complications (neoadjuvant or/and adjuvant therapies).

In the current context of evolution in oncologic surgery and reconstruction techniques, the identification of factors associated with complications and reconstruction failure could help to find the optimal "oncoplastic" technique for 
the individual patient, increasing oncologic efficacy and good aesthetic results, as well as reducing the failure rate.

\section{Authors' Contributions}

TS and IR: Conceptualization, data curation, formal analysis, investigation, funding acquisition, writing original draft and editing. MG and AV: Data curation, formal analysis, critical review. AI and GLR: Data curation, critical review, editing. JN, EV and SB: Methodology, formal analysis, investigation.

\section{Conflicts of Interest}

All Authors declare that there is no conflict of interest regarding this study.

\section{References}

1 Torre LA, Bray F, Siegel RL, Ferlay J, Lortet-Tieulent J and Jemal A: Global cancer statistics, 2012. CA Cancer J Clin 65(2): 87-108, 2015. PMID: 25651787. DOI: 10.3322/caac.21262

2 Akram M and Siddiqui SA: Breast cancer management: past, present and evolving. Indian J Cancer 49(3): 277-282, 2012. PMID: 23238144. DOI: 10.4103/0019-509X.104486

3 Veronesi U, Saccozzi R, Del Vecchio M, Banfi A, Clemente C, De Lena M, Gallus G, Greco M, Luini A, Marubini E, Muscolino G, Rilke F, Salvadori B, Zecchini A and Zucali R: Comparing radical mastectomy with quadrantectomy, axillary dissection, and radiotherapy in patients with small cancers of the breast. N Engl J Med 305(1): 6-11, 1981. PMID: 7015141. DOI: 10.1056/NEJM198107023050102

4 Fisher B, Anderson S, Bryant J, Margolese RG, Deutsch M, Fisher ER, Jeong JH and Wolmark N: Twenty-year follow-up of a randomized trial comparing total mastectomy, lumpectomy, and lumpectomy plus irradiation for the treatment of invasive breast cancer.. N Engl J Med 347(16): 1233-1241, 2002. PMID: 12393820. DOI: $10.1056 /$ NEJMoa022152

5 Early Breast Cancer Trialists' Collaborative Group (EBCTCG), Darby S, McGale P, Correa C, Taylor C, Arriagada R, Clarke M, Cutter D, Davies C, Ewertz M, Godwin J, Gray R, Pierce L, Whelan T, Wang Y and Peto R: Effect of radiotherapy after breastconserving surgery on 10-year recurrence and 15-year breast cancer death: meta-analysis of individual patient data for 10,801 women in 17 randomised trials. Lancet 378(9804): 1707-1716, 2011. PMID: 22019144. DOI: 10.1016/S0140-6736(11)61 629-2

6 Plesca M, Bordea C, El Houcheimi B, Ichim E and Blidaru A: Evolution of radical mastectomy for breast cancer. J Med Life 9(2): 183-186, 2016. PMID: 27453752.

7 Rancati A, Gonzalez E, Dorr J and Angrigiani C: Oncoplastic surgery in the treatment of breast cancer. Ecancermedicalscience 7: 293, 2013. PMID: 23441139. DOI: 10.3332/ecancer.2013.293

8 Veronesi U, Stafyla V, Petit JY and Veronesi P: Conservative mastectomy: extending the idea of breast conservation. Lancet Oncol 13(7): 311-317, 2012. PMID: 22748270. DOI: 10.1016/ S1470-2045(12)70133-X

9 Kummerow KL, Du L, Penson DF, Shyr Y and Hooks MA: Nationwide trends in mastectomy for early-stage breast cancer. JAMA Surg 150(1): 9-16, 2015. PMID: 25408966. DOI: 10.1001/jamasurg.2014.2895
10 Mahmood U, Hanlon AL, Koshy M, Buras R, Chumsri S, Tkaczuk KH, Cheston SB, Regine WF and Feigenberg SJ: Increasing national mastectomy rates for the treatment of early stage breast cancer. Ann Surg Oncol 20(5): 1436-1443, 2013. PMID: 23135312. DOI: 10.1245/s10434-012-2732-5

11 Dragun AE, Huang B, Tucker TC and Spanos WJ: Increasing mastectomy rates among all age groups for early stage breast cancer: a 10-year study of surgical choice. Breast J 18(4): 318-325, 2012. PMID: 22607016. DOI: 10.1111/j.1524-4741.2012.01245.x

12 Mota BS, Riera R, Ricci MD, Barrett J, de Castria TB, Atallah ÁN and Bevilacqua JL: Nipple- and areola-sparing mastectomy for the treatment of breast cancer. Cochrane Database Syst Rev 11: CD008932, 2016. PMID: 27898991. DOI: 10.1002/14651 858.CD008932.pub3

13 Rice $\mathrm{CO}$ and Strickler JH: Adeno-mammectomy for benign breast lesions. Surg Gynecol Obstet 93(6): 759-762, 1951. PMID: 14893082.

14 Nava MB, Cortinovis U, Ottolenghi J, Riggio E, Pennati A, Catanuto G, Greco $\mathrm{M}$ and Rovere GQ: Skin-reducing mastectomy. Plast Reconstr Surg 118(3): 603-610, 2006. PMID: 16932166. DOI: 10.1097/01.prs.0000233024.08392.14

15 Curigliano G, Burstein HJ, Winer EP, Gnant M, Dubsky P, Loibl S, Colleoni M, Regan MM, Piccart-Gebhart M, Senn H-J and Thürlimann B: De-escalating and escalating treatments for earlystage breast cancer: the St. Gallen International Expert Consensus Conference on the Primary Therapy of Early Breast Cancer 2017. Ann Oncol 28(8): 1700-1712, 2017. PMID: 288 38210. DOI: $10.1093 /$ annonc/mdx806

16 Reddy KG, Strassle PD and McGuire KP: Role of age, tumor grade, and radiation therapy on immediate postmastectomy breast reconstruction. Clin Breast Cancer 18(4): 313-319, 2018. PMID: 29305307. DOI: 10.1016/j.clbc.2017.11.021

$17 \mathrm{Wu} \mathrm{W}$, Cheng S, Deng H, Wu J, Mao K and Cao M: Impact of breast cancer subtype defined by immunohistochemistry hormone receptor and HER2 status on the incidence of immediate postmastectomy reconstruction. Medicine (Baltimore) 95(3): 2547, 2016. PMID: 26817902. DOI: 10.1097/MD 000000 0000002547

18 Medina-Franco H, Vasconez LO, Fix RJ, Heslin MJ, Beenken SW, Bland KI and Urist MM: Factors associated with local recurrence after skin-sparing mastectomy and immediate breast reconstruction for invasive breast cancer. Ann Surg 235(6): 814-819, 2002. PMID: 12035037. DOI: 10.1097/00000658-2002 06000-00008

19 Katipamula R, Degnim AC, Hoskin T, Boughey JC, Loprinzi C, Grant CS, Brandt KR, Pruthi S, Chute CG, Olson JE, Couch FJ, Ingle JN and Goetz MP: Trends in mastectomy rates at the Mayo Clinic Rochester: effect of surgical year and preoperative magnetic resonance imaging. J Clin Oncol 27(25): 4082-4088, 2009. PMID: 19636020. DOI: 10.1200/JCO.2008.19.4225

20 McGuire KP, Santillan AA, Kaur P, Meade T, Parbhoo J, Mathias M, Shamehdi C, Davis M, Ramos D and Cox CE: Are mastectomies on the rise? A 13-year trend analysis of the selection of mastectomy versus breast conservation therapy in 5865 patients. Ann Surg Oncol 16(10): 2682-2690, 2009. PMID: 19653046. DOI: 10.1245/s10434-009-0635-x

21 Muller T, Baratte A, Bruant-Rodier C, Bodin F and Mathelin C: Oncological safety of nipple-sparing prophylactic mastectomy: A review of the literature on 3716 cases. Ann Chir Plast Esthet 63(3): 6-13, 2018. PMID: 29030030. DOI: 10.1016/j.anplas. 2017.09.005 
22 Kim H, Mun GH, Wiraatmadja ES, Lim SY, Pyon JK, Oh KS, Lee JE, Nam SJ and Bang SI: Preoperative magnetic resonance imaging-based breast volumetry for immediate breast reconstruction. Aesthetic Plast Surg 39(3): 369-376, 2015. PMID: 25924697. DOI: 10.1007/s00266-015-0493-9

23 Albornoz CR, Bach PB, Mehrara BJ, Disa JJ, Pusic AL, McCarthy CM, Cordeiro PG and Matros E: A paradigm shift in U.S. Breast reconstruction: increasing implant rates. Plast Reconstr Surg 131(1): 15-23, 2013. PMID: 23271515. DOI: 10.1097/PRS.0b013e3182729cde

24 Seki T, Jinno H, Okabayashi K, Murata T, Matsumoto A, Takahashi M, Hayashida T and Kitagawa Y: Comparison of oncological safety between nipple sparing mastectomy and total mastectomy using propensity score matching. Ann R Coll Surg Engl 97(4): 291-297, 2015. PMID: 26263938. DOI: 10.1308/003588415X14181254788881

25 Rocco N, Catanuto G and Nava MB: What is the evidence behind conservative mastectomies? Gland Surg 4(6): 506-518, 2015. PMID: 26645005. DOI: 10.3978/j.issn.2227-684X.2015. 04.19

26 Downes KJ, Glatt BS, Kanchwala SK, Mick R, Fraker DL, Fox KR, Solin LJ, Bucky LP and Czerniecki BJ: Skin-sparing mastectomy and immediate reconstruction is an acceptable treatment option for patients with high-risk breast carcinoma. Cancer 103(5): 906-913, 2005. PMID: 15651068. DOI: 10.1002/ cncr.20851
27 Schaverien MV and Munnoch DA: Effect of neoadjuvant chemotherapy on outcomes of immediate free autologous breast reconstruction. Eur J Surg Oncol 39(5): 430-436, 2013. PMID: 23466245. DOI: 10.1016/j.ejso.2013.02.015

28 Sbitany H, Wang F, Peled AW, Lentz R, Alvarado M, Ewing CA, Esserman LJ, Fowble B and Foster RD: Immediate implantbased breast reconstruction following total skin-sparing mastectomy: defining the risk of preoperative and postoperative radiation therapy for surgical outcomes. Plast Reconstr Surg 134(3): 396-404, 2014. PMID: 25158699. DOI: 10.1097/ PRS.0000000000000466

29 Kronowitz SJ and Robb GL: Radiation therapy and breast reconstruction: a critical review of the literature. Plast Reconstr Surg 124(2): 395-408, 2009. PMID: 19644254. DOI: 10.1097/PRS.0b013e3181aee987
Received August 12, 2019

Revised August 30, 2019 Accepted September 12, 2019 